\title{
Dimensões lineares da folha e seu uso na determinação do perfil vertical foliar de gladíolo
}

\author{
Natalia Teixeira Schwab; Nereu Augusto Streck (*); Amanda Rehbein; Bruna San Martin Rolim \\ Ribeiro; Lilian Osmari Ulhmann; Josana Andréa Langner; Camila Coelho Becker
}

Universidade Federal de Santa Maria (UFSM), Av. Roraima, 1000, 97105-900 Santa Maria (RS), Brasil.

$\left.{ }^{*}\right)$ Autor correspondente: nstreck2@yahoo.com.br

Recebido: 13/jan./2014; Aceito: 3/mar./2014

\begin{abstract}
Resumo
O gladíolo, importante flor de corte, é uma planta herbácea e suas folhas apresentam formato de lança. Os objetivos do trabalho foram determinar um modelo matemático empírico que melhor estima a área da folha do gladíolo a partir de dimensões lineares e aplicar o modelo matemático para determinar o perfil vertical da área das folhas de diferentes posições na planta. Para isso foi realizado um experimento de campo em Santa Maria com quatro cultivares de gladíolo (Peter Pears, Rose Friendship, Jester e Amsterdã), sendo coletadas 50 folhas de cada cultivar, das quais mensuraram-se o comprimento (C) e a maior largura (L). Em seguida, fotocopiou-se cada folha em um scanner, calculando-se a área individual (AF) com auxílio de um software. A relação entre área e as dimensões das folhas foi ajustada no modelo potência e a capacidade preditiva das equações foi avaliada por várias estatísticas. Resultados indicam que o modelo $A F=$ a (C.L) é o mais indicado para a estimativa da área foliar em gladíolo, podendo-se utilizar a = 0,644 para as quatro cultivares testadas. As menores folhas estão nas posições basais e apicais e as maiores, na posição intermediária da planta.
\end{abstract}

Palavra-chave: Gladiolus grandiflorus, Palma-de-Santa-Rita, floricultura, área fotossintetizante.

\section{Linear dimensions of leaves and its use for estimating the vertical profile of leaf area in gladiolus}

\section{Abstract}

Gladiolus, an important cut flower, is a herbaceous plant that has sword-shaped leaves. The objectives of this study are to determinate an empirical model to estimate the area of gladiolus leaves from its linear dimensions and to apply this model to estimate the vertical profile of leaf area in different position on the plant. A field experiment was conducted in Santa Maria, RS, Brazil, with four gladiolus cultivars (Peter Pears, Rose Friendship, Jester and Amsterdam). A total of fifty leaves from each cultivar were collected and their width $(C)$ and length $(\mathrm{L})$ measured. Each leaves have then their area (AF) measured digitally. The relationship between area and dimensions of each leaf was fitted to a power model and the performance of the equations was evaluated by several statistics. Results indicates that the model $A F=a .(C$. L) is the best model to estimate leaf area in gladiolus, with $\mathrm{a}=0.664$ for the four cultivars. Smaller leaves are ate the bottom and at the upper position and larger leaves are ate intermediate position on the plant.

Key words: Gladiolus grandiflorus, Sword lily, floriculture, photosynthetic area. 


\section{INTRODUÇÃO}

O gladíolo ou palma-de-Santa-Rita (Gladiolus $\mathrm{x}$ grandiflorus Hort.) é uma importante flor de corte (Choudhary et al., 2011) cultivada na maioria dos países tropicais e subtropicais (Ahmad et al., 2011). Ocupa a oitava posição mundial no comércio de flores de corte (Ahmad et al., 2008) e no Brasil tem maior consumo em Finados. É uma planta herbácea, perene de ciclo anual, propagada por cormos e com folhas simples em formato de lança.

Como com outras culturas agrícolas, estudos básicos do crescimento e desenvolvimento vegetal de espécies florícolas são importantes, pois tais estudos explicam o rendimento final da cultura e auxiliam no refinamento de práticas de manejo para maximizar a eficiência de ecossistemas com o mínimo de impacto ambiental. Dentre os parâmetros de crescimento vegetal, a área das folhas representa um dos mais importantes, pois está relacionada à interceptação da radiação solar, a qual é responsável pela produção de fotoassimilados que implicarão diretamente na produtividade biológica e econômica da cultura. $\mathrm{O}$ índice de área foliar (IAF) é um dos índices ecofisiológicos mais utilizados em estudos da dinâmica do crescimento e desenvolvimento de folhas, representando a área total das folhas pela área de solo que cada planta ocupa na lavoura. No entanto, nem todas as folhas que compóem o IAF estão diretamente expostas à radiação solar, pois existe um perfil vertical de distribuição da área das folhas que varia com sua posição na haste (Fagundes et al., 2009). Em gladíolo, a inserção das folhas é a partir de pontos muito próximos, que saem de um caule subterrâneo expandido denominado cormo.

A área foliar de uma planta depende do número e do tamanho das folhas e pode ser determinada a partir de métodos de medição destrutivos (diretos) ou não destrutivos (indiretos) (Marshall, 1968), tais como o uso de aparelho integrador de área foliar, para o primeiro caso, e a partir de medidas lineares do limbo, no caso de método indireto (Aquino et al., 2011). Os métodos destrutivos têm a desvantagem de não serem aplicáveis em casos onde a quantidade de amostras é limitada e/ou quando se pretende manter a avaliação de outros parâmetros em experimentos por um longo período de tempo, o que impossibilita a destruição das unidades experimentais ou parcelas para a realização de medidas diretas da área foliar. Já com os métodos não destrutivos (indiretos) as plantas amostradas são mantidas na parcela e assim pode-se acompanhar o crescimento e a expansão das folhas de uma mesma planta até o final do seu ciclo (Fagundes et al., 2009).

O método indireto de determinação da área de folhas a partir de dimensóes lineares já foi utilizado para diversas culturas agrícolas, como girassol (Aquino et al., 2011), batata (Silva et al., 2008), feijão-caupi (Lima et al., 2008), feijãovagem (Toebe et al., 2012), couve-folha (Marcolini et al., 2005) e também para plantas invasoras, como, por exemplo,
Brachiaria plantaginea (Bianco et al., 2005), Brachiaria subquadripara, Brachiaria mutica (Marchi et al., 2011) e Typha latifolia (Bianco et al., 2003). Como nesse método usam-se modelos ajustados por regressão, os coeficientes são dependentes da espécie e até da cultivar dentro de cada espécie, devendo-se, portanto, determiná-los para cada genótipo. Para o gladíolo não foi encontrado na literatura relato sobre a estimativa da área das folhas a partir de dimensóes lineares, o que constituiu motivação para a realização deste trabalho.

Os objetivos do trabalho foram: a) determinar um modelo matemático empírico que melhor estime a área da folha do gladíolo a partir de dimensôes lineares; e b) aplicar o modelo matemático para determinar o perfil vertical da área das folhas em diferentes posiçóes na planta.

\section{MATERIAL E MÉTODOS}

Um experimento de campo com a cultura do gladíolo foi conduzido em Santa Maria, RS (latitude 29 43'23", longitude $53^{\circ} 43^{\prime} 15^{\prime \prime}$, altitude de $95 \mathrm{~m}$ ). Foram realizados plantios em quatro datas, 18/4/2012, 19/7/2012, 14/9/2012 e 17/7/2013, com as cultivares Peter Pears (ciclo precoce), Rose Friendship (ciclo médio) e Jester (ciclo tardio) nas duas primeiras datas de plantio, Amsterdã (ciclo precoce), Rose Friendship e Jester, na terceira e Peter Pears (ciclo precoce), na quarta data. A adubaçáo foi de $500 \mathrm{~kg} \mathrm{ha}^{-1}$ de NPK 5-20-20, seguindo-se a análise de solo.

As plantas foram cultivadas em canteiros com $1 \mathrm{~m}$ de largura, distribuídas em linhas pareadas espaçadas em 0,40 $\mathrm{m}$ e com espaçamento entre plantas de $0,20 \mathrm{~m}$. Foram realizados tratos culturais indicados para a espécie durante o ciclo de desenvolvimento (Tombolato, 2004).

Para a estimativa das equaçóes que relacionam a área de folhas individuais com duas dimensôes lineares, coletaram-se ao longo do ciclo de desenvolvimento da cultura 50 folhas de diversos tamanhos e posiçóes na planta, de plantas sadias de cada cultivar na primeira (Peter Pears, Rose Friendship e Jester) e na terceira data de plantio (Amsterdã). Tomou-se o cuidado de destacar as folhas na sua inserção, de modo que somente a porçáo fotossinteticamente ativa da folha fosse amostrada.

Após o destacamento foi medido o comprimento (C) e a maior largura (L) de cada folha (Figura 1). O comprimento foi definido como a distância entre o ponto de inserção da folha no limbo foliar da folha antecedente e a extremidade oposta da folha e a largura, como a maior dimensão perpendicular ao eixo do comprimento. Em seguida, cada folha foi fotocopiada em um scanner e a área individual de cada folha (AF) foi calculada com auxílio do software Quant, versão 1.0.1 (2003). A relaçáo entre área da folha e suas dimensóes lineares foi ajustada ao modelo potência considerando-se as dimensóes lineares, individualmente, e o seu produto pelas equaçôes 1,2 e 3 : 


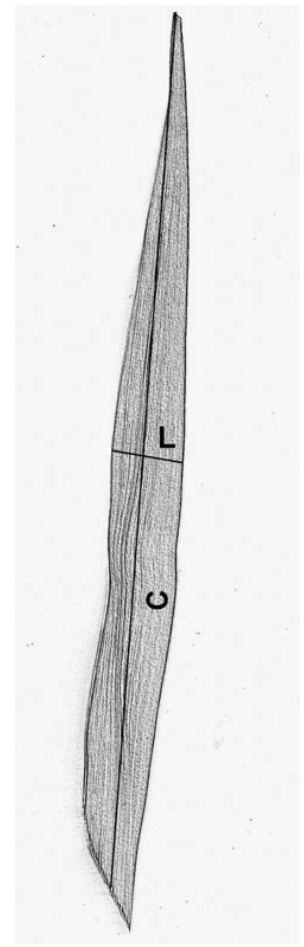

Figura 1. Folha de gladíolo com as dimensôes lineares comprimento (C) e largura (L).

$\mathrm{AF}=\mathrm{a} \cdot(\mathrm{L})^{\mathrm{b}}$

$\mathrm{AF}=\mathrm{a} \cdot(\mathrm{C})^{\mathrm{b}}$

$\mathrm{AF}=\mathrm{a} \cdot(\mathrm{L} \cdot \mathrm{C})^{\mathrm{b}}$

em que $\mathrm{AF}$ é a área da folha $\left(\mathrm{cm}^{2}\right)$, $\mathrm{L}$ é a maior largura da folha $(\mathrm{cm}), \mathrm{C}$ é o comprimento da folha $(\mathrm{cm}), a$ é o coeficiente de forma e $b$ é o coeficiente potência.

Optou-se pelo modelo potência em função de ele, quando comparado a outros modelos, ser frequentemente o que melhor ajusta a relação AF e dimensões lineares em diferentes culturas agrícolas (Aquino et al., 2011; Cargnelutti Filho et al., 2012; Toebe et al., 2012). Além disso, o modelo potência é bastante flexível em termos de forma de resposta, a qual é dada pelo coeficiente $b$. Quando o coeficiente $b$ é menor que 1 , a relaçáo entre a variável resposta e o preditor é saturante em relação ao preditor; quando $b$ é igual a 1 , a relação é proporcional indefinidamente.

Os coeficientes $a$ e $b$ das equaçóes 1,2 e 3 foram estimados por regressão não linear, forçando-se a relação entre área e dimensão da folha a passar pela origem, usando-se o software Excel $^{\mathrm{TM}}$. Na equação 3 considerou-se $\mathrm{b}=1$, pois a folha de gladíolo tem formato lanceolado e também por que na maioria dos trabalhos em que a área da folha foi estimada a partir do produto das duas dimensóes lineares da folha em diversas espécies vegetais foi utilizado o modelo da regressáo linear simples, $y=a x$ (Bianco et al., 2005; Fagundes et al., 2009; Silva et al., 2008). Matematicamente, utilizar o coeficiente $\mathrm{b}=1$ na relação entre $\mathrm{a}$ área da folha e o produto entre as duas dimensôes lineares também é desejável e apropriado, pois nesse caso o coeficiente de forma da equação 3 representa a fração da área da folha em relação à área do retângulo de lados C e L.

Para testar o desempenho das equaçôes 1, 2 e 3, foram coletadas 50 folhas das cultivares Amsterdã, Rose Friendship e Jester no experimento com plantio em 14/9/2012 e da cultivar Peter Pears com plantio em 17/7/2013, as quais constituem dados independentes. O desempenho das equaçóes 1,2 e 3 foi avaliado pelas estatísticas: erro médio absoluto (EMA) - equação 4; raiz quadrada média do erro (RQME) - equação 5; índice BIAS - equação 6; índice de concordância (d) - equaçáo 7 ; índice de confiança ou desempenho (c) - equação 8; coeficiente de correlação (r) - equação 9; e índice de concordância modificado (d1) - equação (10):

EMA $=\frac{\sum_{\mathrm{i}=1}^{\mathrm{N}}|\mathrm{Si}-\mathrm{Oi}|}{\mathrm{N}}$

$\mathrm{RQME}=\sum_{\mathrm{i}=1}^{\mathrm{N}} \frac{(\mathrm{Si}-\mathrm{Oi})^{2}}{\mathrm{~N}}$

$\mathrm{BIAS}=\frac{\sum_{\mathrm{i}=1}^{\mathrm{N}} \mathrm{Si}-\sum_{\mathrm{i}=1}^{\mathrm{N}} \mathrm{Oi}}{\sum_{\mathrm{i}=1}^{\mathrm{N}} \mathrm{Oi}}$

$\mathrm{d}=1-\left[\frac{\sum_{\mathrm{i}=1}^{\mathrm{N}}(\mathrm{Si}-\mathrm{Oi})^{2}}{\sum_{\mathrm{i}=1}^{\mathrm{N}}\left(\left|\mathrm{Si}^{\prime}\right|+\left|\mathrm{Oi}^{\prime}\right|\right)^{2}}\right]$

$\mathrm{c}=\mathrm{r} \cdot \mathrm{d}$

$\mathrm{r}=\frac{\mathrm{a} \sum \mathrm{Si}+\mathrm{b} \sum \mathrm{Si} \cdot \mathrm{Oi}-\mathrm{N}(\overline{\mathrm{Si}})^{2}}{\sum \mathrm{Si}^{2}-\mathrm{N}(\overline{\mathrm{Si}})^{2}}$

$\mathrm{dl}=1-\left[\frac{\sum_{\mathrm{i}=1}^{\mathrm{N}}|\mathrm{Si}-\mathrm{Oi}|}{\sum_{\mathrm{i}=1}^{\mathrm{N}}\left(\left|\mathrm{Si}^{\prime}\right|+\left|\mathrm{Oi}^{\prime}\right|\right)}\right]$

Nas equaçốes 4, 5, 6, 7, 9 e 10 Si representa os valores estimados, $\mathrm{Oi}$ os valores observados e $\mathrm{N}$ o número de observaçôes, onde ì $^{\prime}=\mathrm{Si}-\overline{\mathrm{O}} \mathrm{e}$ Oi' $=\mathrm{Oi}-\overline{\mathrm{O}}$. Na equação 9, $\mathrm{b}=\frac{\mathrm{sOiSi}}{\mathrm{sOiOi}}, \mathrm{a}=\overline{\mathrm{Si}}-\mathrm{b} . \overline{\mathrm{O}} \mathrm{i}, \mathrm{sOiSi}=\sum \mathrm{Oi} . \mathrm{Si}-\frac{\sum \mathrm{Oi} . \mathrm{Si}}{\mathrm{N}} \mathrm{e}$ sOiOi $\sum \mathrm{Oi}^{2}-\frac{\left(\sum \mathrm{Oi}\right)^{2}}{\mathrm{~N}}$

O EMA e a RQME expressam a magnitude do erro produzido pelo modelo, de modo que quanto mais próximas de zero essas duas estatísticas, melhor é o modelo. $\mathrm{O}$ EMA é menos sensível para valores extremos do que a RQME, uma vez que não eleva ao quadrado a diferença entre os valores estimados e os observados. O índice BIAS expressa o desvio médio dos valores estimados em relação aos valores observados, indicando assim a tendência de o modelo superestimar ou subestimar os valores estimados e, portanto, quanto mais próximo de zero essa estatística, 
menor é a magnitude do erro sistemático do modelo (Leite e Andrade, 2002). O índice $d$ é uma medida de quanto o modelo está livre de erro, quanto mais próximo de 1, menor erro apresenta essa estimativa (Willmott, 1981). Os valores do índice $d$ variam de 0 (zero), para nenhuma concordância, a 1, para a concordância perfeita. $O$ índice de confiança ou desempenho (c), proposto por Camargo e Sentelhas (1997), indica o desempenho dos métodos, quanto mais próximo de 1, melhor é o desempenho do modelo.

O coeficiente de correlação (r) indica o grau de dispersão e associação dos dados simulados em relação aos dados observados. Quanto mais próximo de 1, mais correlacionados serão os dados simulados e observados. Além dessas estatísticas, a relação entre dados de área de folhas medida e calculada foi submetida a análise de regressão simples do modelo $\mathrm{y}=\mathrm{a}+\mathrm{bx}$, em que $a$ é o coeficiente linear (considerado 0 (zero) na análise, para forçar o modelo a passar pela origem) e $b$ é o coeficiente angular, o qual deve ser o mais próximo possível da unidade. O índice $d 1$ (Equação 10) é uma modificação do índice $d$ (Equação 7) sugerida por Willmott et al. (1985), pois a utilização da função quadrática na equação 7 pode resultar em valores elevados desse índice e, portanto, a modificação proposta tende a resultar em um índice mais rigoroso Os valores do índice $d 1$ variam de 0 (zero), para nenhuma concordância, à 1 , para a concordância perfeita.

A fim de testar a aplicabilidade do modelo com melhor desempenho para quantificar o perfil da distribuição da área das folhas de diferentes posiçôes na planta de gladíolo, esse modelo foi aplicado a dados de dimensóes lineares das folhas individuais coletadas na época de floração, quando todas as folhas estavam expandidas, nas cultivares Rose Friendship, Peter Pears e Jester, em um outro experimento conduzido em Santa Maria, RS, com datas de plantio 2/9/2011, 4/1/2012 e 1.\%/6/2012. As práticas de manejo usadas nesse experimento foram as mesmas realizadas no experimento anterior.

\section{RESULTADOS E DISCUSSÃO}

Na figura 2 estão plotados os dados de área da folha versus sua largura (L), comprimento $(\mathrm{C})$ e o produto comprimento $\mathrm{x}$ largura (C.L) e as equaçóes ajustadas para cada modelo (Equaçóes 1, 2 e 3, respectivamente). Quando apenas uma das dimensóes lineares ( $\mathrm{L}$ ou $\mathrm{C}$ ) é usada como preditor, o coeficiente $b$ das equações 1 e 2 é maior que 1 , indicando relação não linear entre as duas variáveis, mas sem saturação na faixa de valores medidos. Quando o preditor da área foliar é o produto entre a largura e o comprimento da folha, a relação passa a ser linear, com maior coeficiente de determinação, sugerindo que para estimar a área da folha do gladíolo é mais indicado utilizarem-se as duas dimensôes da folha do que apenas uma delas.
O desempenho da equação 3 com os coeficientes angulares indicados nas figuras $2 \mathrm{c}, \mathrm{f}, \mathrm{i}$ e $\mathrm{m}$ foi melhor do que o das outras duas equaçóes com dados dependentes (Figura 3). Os pontos estão muito mais próximos da linha 1:1 e os coeficientes angulares de determinação $\left(\mathrm{R}^{2}\right)$ são muito próximos de 1 quando foi usado o produto entre comprimento e largura da folha (Figuras 3c, f, i, m).

$\mathrm{Na}$ tabela 1 estão as estatísticas da capacidade preditiva das equaçôes 1,2 e 3 com os coeficientes indicados na figura 2 . Todas as estatísticas confirmam que a melhor equação para estimar a área da folha do gladíolo é a que usa o produto do comprimento e largura da folha (Equação 3), com EMA variando de 6,2 a $8,5 \mathrm{~cm}^{2} /$ folha e RQME variando de 8,1 a $13,6 \mathrm{~cm}^{2} /$ folha.

O coeficiente $a$ da equação 3 variou de 0,6269 a 0,6976 entre as quatro cultivares, uma variação pequena $(0,0707)$ entre as cultivares de ciclo precoce a tardio. Essa pequena variação indica que o formato lanceolado das folhas das quatro cultivares é similar. Em função da pequena variação do coeficiente $a$, foi ajustada uma única equação 3 para os dados das quatro cultivares e depois essa nova equação geral foi testada com os dados independentes de cada cultivar. A equação ajustada para todas as cultivares juntas foi $\mathrm{AF}=0,664$ (C.L), com $\mathrm{R}^{2}=0,9325$, e as estatísticas de desempenho dessa equação estão na parte inferior da tabela 1 . Comparando-se as estatísticas de desempenho da equação 3 com o coeficiente $a$ de cada cultivar com as estatísticas utilizando-se a equação 3 com o coeficiente $\mathrm{a}=0,664$ nota-se que o erro é similar, inclusive as estatísticas para as cultivares Rose Friendship, Peter Pears e Amsterdã mostram melhor desempenho da equaçáo 3 com o coeficiente $\mathrm{a}=0,664$. Esses resultados indicam que se pode usar uma equação geral para mais de uma cultivar de gladíolo. Isso é importante, pois a cada ano são lançadas novas cultivares de gladíolo, mas se o formato das folhas dessas cultivares é similar ao formato de folhas de cultivares anteriores, então não é necessário estimar o coeficiente $a$ da equação 3 com tanta frequência.

$\mathrm{Na}$ figura 4 é apresentado o perfil vertical da área da folha das cultivares Rose Friendship, Peter Pears e Jester em três datas de plantio, calculadas com a equaçáo 3, e o coeficiente $a$ para cada cultivar, indicados nas figuras $2 \mathrm{c}$, $\mathrm{f}, \mathrm{i}, \mathrm{m}$ (barras preenchidas) e com a equação $\mathrm{AF}=0,644$ (C.L) (barras vazias). Para uma mesma data de plantio, o perfil vertical da área foliar tem um padrão similar, com as folhas basais e apicais sendo menores que as folhas nas posiçôes intermediárias.

Comparando-se as épocas de cultivo, a área das folhas foi maior no plantio de 2/9/2011, quando o crescimento das folhas ocorreu no mês de outubro e novembro, época em que a radiação solar incidente foi elevada e as temperaturas amenas. Comparando-se a área de folhas calculada com a equaçáo 3 e o coeficiente $a$ dependente do genótipo (barras preenchidas) e a área calculada com a equação geral para as quatro cultivares (barras vazias), nota-se que a diferença é 

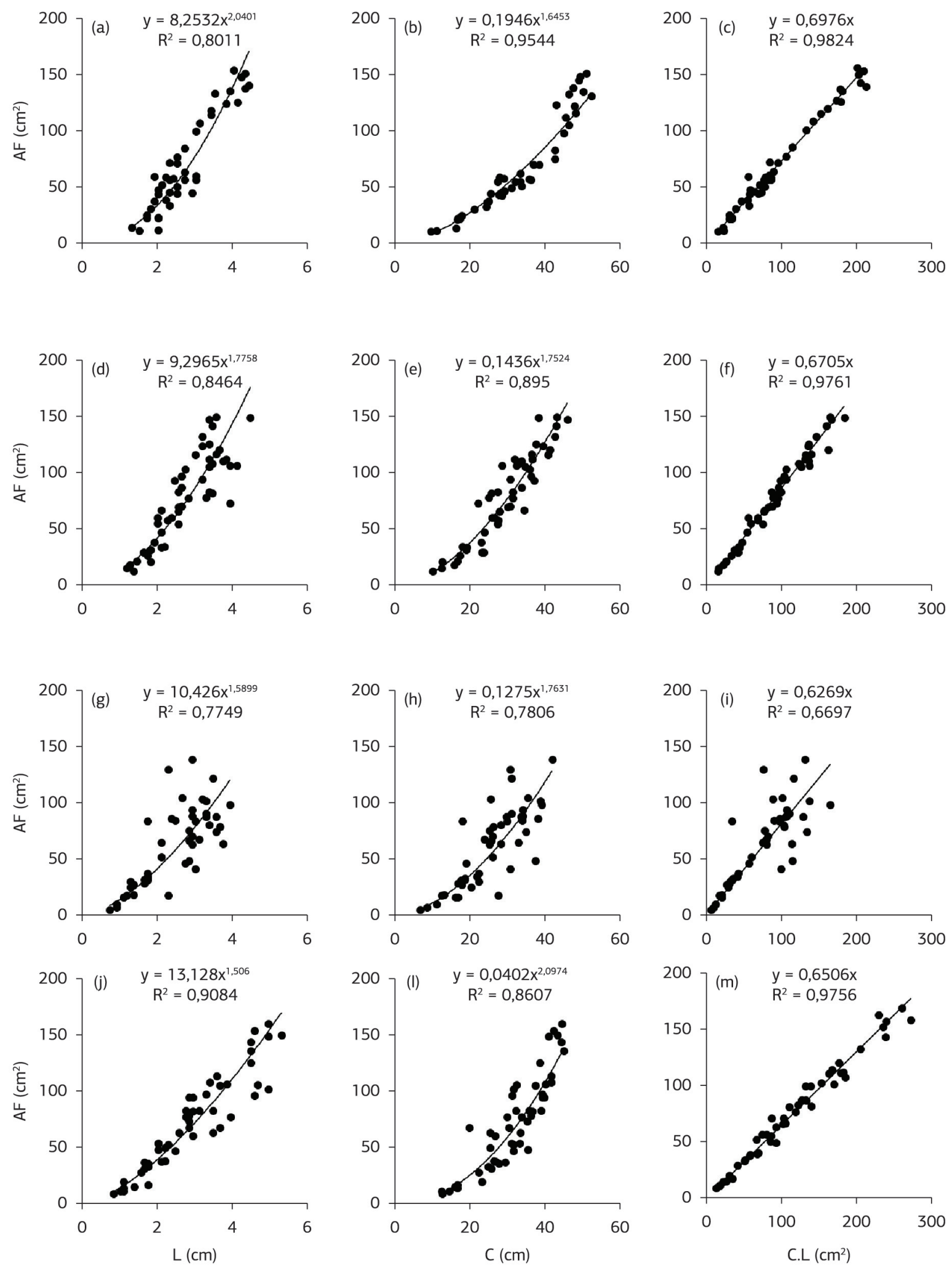

Figura 2. Relação entre área da folha (AF) de gladíolo e suas dimensóes lineares largura (L), comprimento (C) e o produto (C.L) para as cultivares Jester (a, b, c), Rose Friendship (d, e, f), Peter Pears (g, h, i) e Amsterdã (j, l, m); a curva e a equação ajustada em cada painel são modelos indicados nas equaçóes 1,2 e 3 , respectivamente. 
Tabela 1. Estatísticas do desempenho dos modelos empíricos de estimativa da área da folha (AF) de gladíolo a partir de suas dimensôes lineares comprimento (C) e largura (L), com dados independentes

\begin{tabular}{|c|c|c|c|c|c|c|c|}
\hline \multirow{3}{*}{ Cultivar } & \multicolumn{7}{|c|}{ Estatísticas* } \\
\hline & EMA & RQME & BIAS & d & C & $\mathbf{r}$ & d1 \\
\hline & \multicolumn{7}{|c|}{ Modelo AF = a. $(\mathrm{L})^{\mathrm{b}}$} \\
\hline Jester & 25,38 & 35,93 & $-0,1779$ & 0,8407 & 0,78025 & 0,9281 & 0,6843 \\
\hline Rose Friendship & 23,54 & 28,05 & 0,3382 & 0,8792 & 0,80007 & 0,9100 & 0,6743 \\
\hline Peter Pears & 13,18 & 16,80 & 0,1080 & 0,9620 & 0,84670 & 0,8803 & 0,8182 \\
\hline \multirow[t]{2}{*}{ Amsterdã } & 13,45 & 16,34 & 0,0768 & 0,9716 & 0,93788 & 0,9653 & 0,8231 \\
\hline & \multicolumn{7}{|c|}{ Modelo AF $=\mathrm{a} .(\mathrm{C})^{\mathrm{b}}$} \\
\hline Jester & 19,27 & 25,08 & 0,2190 & 0,8960 & 0,7383 & 0,8960 & 0,6041 \\
\hline Rose Friendship & 22,66 & 27,90 & $-0,1875$ & 0,9264 & 0,8343 & 0,9264 & 0,7207 \\
\hline Peter Pears & 24,40 & 28,77 & 0,2216 & 0,8708 & 0,7694 & 0,8835 & 0,6294 \\
\hline \multirow[t]{2}{*}{ Amsterdã } & 26,28 & 34,44 & 0,0658 & 0,8780 & 0,7449 & 0,8780 & 0,7866 \\
\hline & \multicolumn{7}{|c|}{ Modelo AF = a. (C.L) } \\
\hline Jester & 6,315 & 10,52 & 0,0110 & 0,9768 & 0,9301 & 0,9522 & 0,9034 \\
\hline Rose Friendship & 8,060 & 12,45 & 0,0014 & 0,9788 & 0,9384 & 0,9587 & 0,9023 \\
\hline Peter Pears & 6,236 & 8,142 & 0,0562 & 0,9916 & 0,8115 & 0,8184 & 0,9177 \\
\hline \multirow[t]{2}{*}{ Amsterdã } & 8,546 & 13,62 & 0,0577 & 0,9793 & 0,9446 & 0,9646 & 0,9311 \\
\hline & \multicolumn{7}{|c|}{ Modelo AF = 0,664. (C.L) } \\
\hline Jester & 6,6371 & 10,42 & 0,06693 & 0,9795 & 0,9459 & 0,9657 & 0,8822 \\
\hline Rose Friendship & 6,930 & 9,21 & $-0,0031$ & 0,9888 & 0,9549 & 0,9657 & 0,9013 \\
\hline Peter Pears & 4,978 & 6,23 & 0,0003 & 0,9954 & 0,9612 & 0,9657 & 0,9371 \\
\hline Amsterdã & 5,240 & 7,31 & $-0,0087$ & 0,9941 & 0,9560 & 0,9657 & 0,9313 \\
\hline
\end{tabular}

*EMA = erro médio absoluto $\left(\mathrm{cm}^{2} /\right.$ folha $) ;$ RQME = raiz quadrada média do erro $\left(\mathrm{cm}^{2} /\right.$ folha $) ; \mathrm{BIAS}=$ índice BIAS; $\mathrm{d}=$ índice de concordância; $\mathrm{c}=$ índice de confiança; $\mathrm{r}=$ coeficiente de correlação de Pearson; $\mathrm{d} 1$ = índice de concordância modificado.

pequena, variando de 0,65 a $4,92 \mathrm{~cm}^{2} /$ folha (considerandose todas as folhas das três cultivares e três datas de plantio), o que corresponde a uma diferença de $0,97 \%$ a $5,92 \%$ da área foliar total da planta, respectivamente. Esses resultados indicam que para as quatro cultivares de gladíolo testadas neste estudo a área de folhas individuais pode ser estimada com uma única equação que considera o comprimento e a maior largura da folha.

O modelo potência (equaçóes 1 e 2) ajustou melhor os dados de AF versus comprimento e AF versus largura de folhas (Figuras 2a, b, d, e, g, h, j, l). Esses resultados concordam com trabalhos anteriores com outras espécies agrícolas, de que quando apenas uma das dimensões lineares é usada para estimar a área da folha, o modelo potência é o mais adequado (Aquino et al., 2011; Cargnelutti Filho et al., 2012; Toebe et al., 2012). Já quando é utilizado o produto comprimento e largura, o melhor modelo foi o modelo linear ou a equaçáo da reta (polinômio de primeiro grau, equaçáo 3 , Figuras $2 \mathrm{c}, \mathrm{f}, \mathrm{m}$ ), o que também concorda com trabalhos anteriores com outras espécies agrícolas e silvestres (Aquino et al., 2011; Cargnelutti Filho et al., 2012; Fagundes et al.; 2009). Nesse caso, alguns autores consideraram o valor do coeficiente linear (intercepto) no modelo (Aquino et al., 2011; Cargnelutti Filho et al., 2012; Toebe et al., 2012). No presente trabalho, optou-se por forçar o modelo linear a passar pela origem (coeficiente angular igual a 0 -zero) por entender-se que biologicamente é mais apropriado, já que se não há $\mathrm{x}$ (comprimento $\mathrm{x}$ largura é 0 - zero), o que só ocorre quando não há folhas na planta de gladíolo e não pode haver área de folha calculada pelo modelo, similarmente ao que acontece com o modelo potência.

$\mathrm{O}$ erro da estimativa de AF com o modelo que usa o produto de C x L (Tabela 1) em geral é menor para gladíolo comparado com outras culturas como, por exemplo, em girassol, para o qual Aquino et al. (2011) relatam valores de RQME de 39 a $78 \mathrm{~cm}^{2} /$ folha. Em nabo forrageiro, Cargnelutti Filho et al. (2012) relatam valores de EMA de $8,1 \mathrm{a} 20,5 \mathrm{~cm}^{2} /$ folha e RQME de 13,8 a $24,4 \mathrm{~cm}^{2} /$ folha, e em feijão de porco, Toebe et al. (2012) encontraram EMA de 16,9 a $32,7 \mathrm{~cm}^{2} /$ folha e RQME de 22,2 a $42,0 \mathrm{~cm}^{2} /$ folha. Esses resultados indicam que a estimativa de AF em gladíolo pelo comprimento e largura é mais precisa que naquelas espécies, o que pode ser explicado por se tratarem de folhas uniformes e com formato lanceolado bem definido.

$\mathrm{O}$ método não destrutivo de estimativa da área da folha por modelos empíricos de regressáo que usam as dimensóes lineares das folhas geralmente contêm coeficientes que dependem da espécie e até da cultivar dentro da mesma espécie. Essa é uma desvantagem quando novas cultivares são usadas nos experimentos. Aquino et al. (2011) demonstraram que a precisão das equaçóes empíricas na estimativa da $\mathrm{AF}$ não foi reduzida com o uso de uma única equação para duas cultivares de girassol. Os resultados do presente trabalho indicam que a equação $\mathrm{AF}=0,664$ (C.L) pode ser usada para quatro cultivares de gladíolo (Peter Pears, Amsterdã, Rose Friendship e Jester). Esses resultados demonstram que a variação do coeficiente da forma como é usado o produto $\mathrm{C}$ x L das folhas é pequeno dentro da espécie, já que a mesma caracteriza-se por apresentar folhas em formato de lança, não 

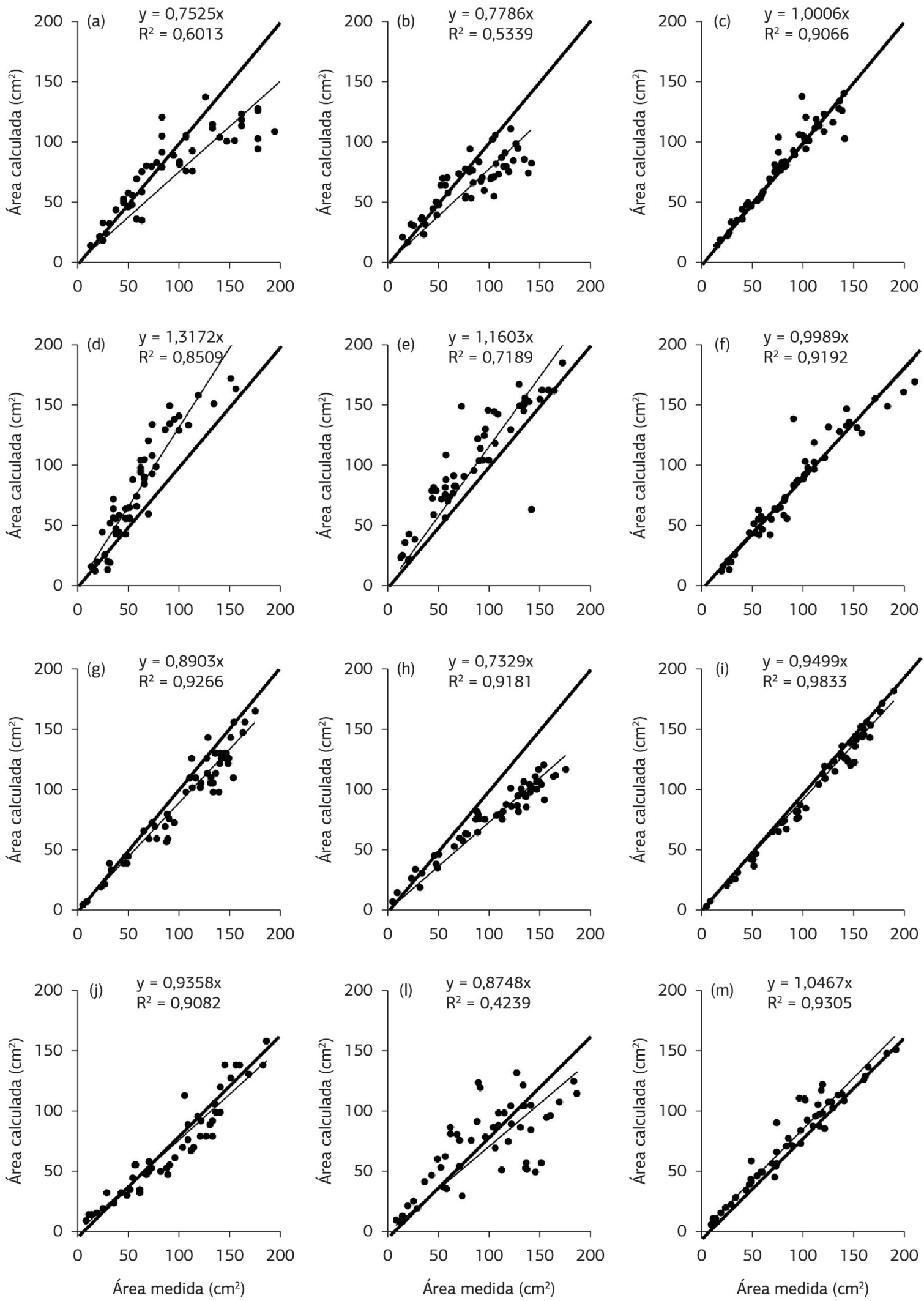

Figura 3. Área da folha calculada pela equação $\left(\mathrm{cm}^{2}\right)$ levando em consideração as dimensóes lineares largura $(\mathrm{L})$, comprimento $(\mathrm{C})$ e o produto (C.L) respectivamente versus a área da folha medida pelo scanner $\left(\mathrm{cm}^{2}\right)$ para as cultivares Jester (a, b, c), Rose Friendship (d, e, f), Peter Pears (g, h, i) e Amsterdã (j, l, m); a equação ajustada em cada painel são modelos indicados na figura 2. 
(a) Data de plantio: 02/09/2011
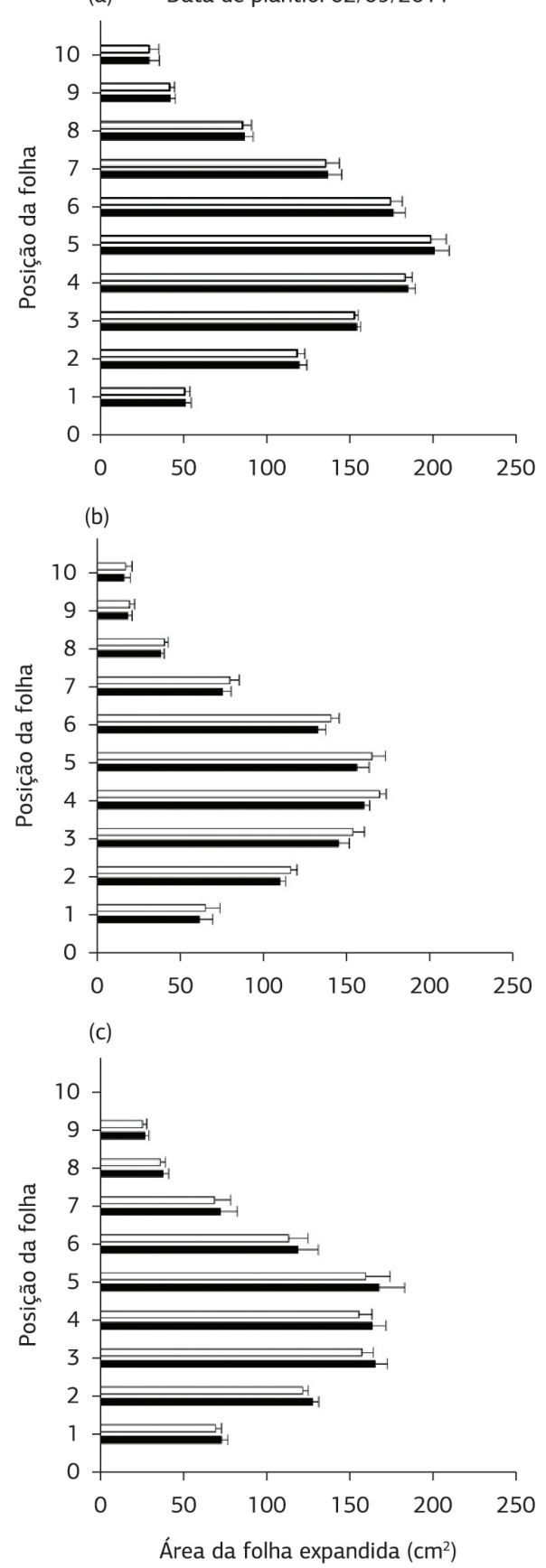

(d) Data de plantio: 04/01/2012

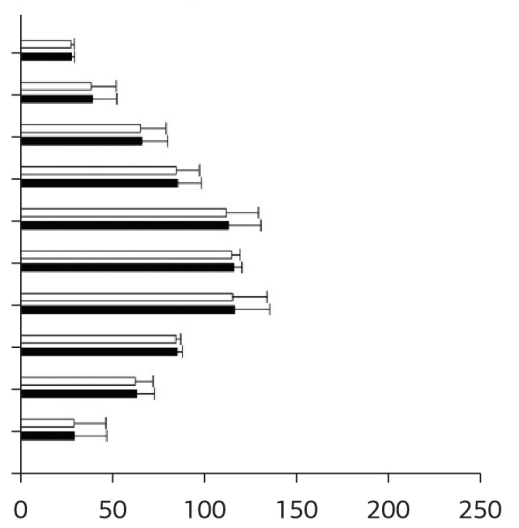

(e)

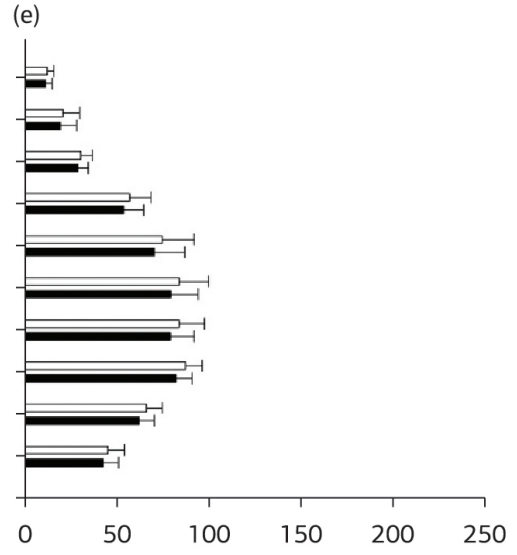

(f)

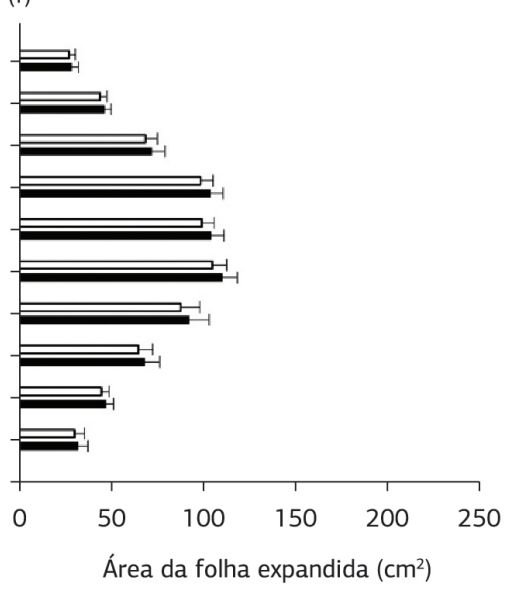

(g) Data de plantio: 01/06/2012

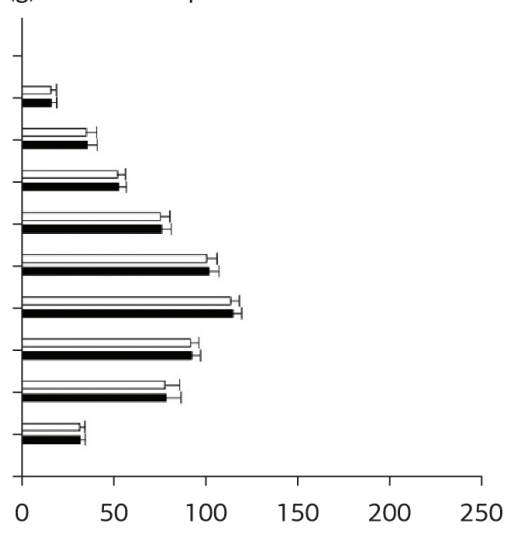

(h)

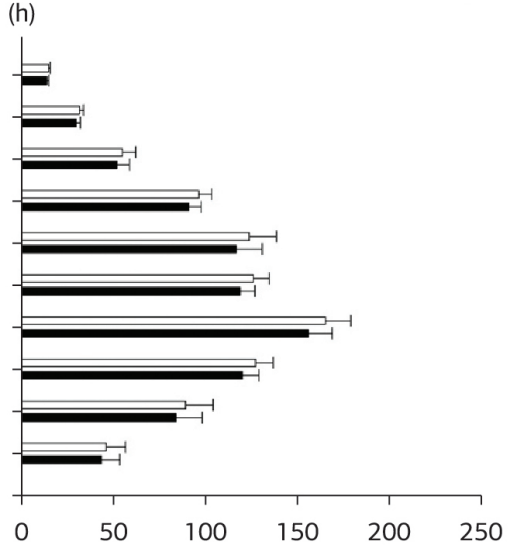

(i)

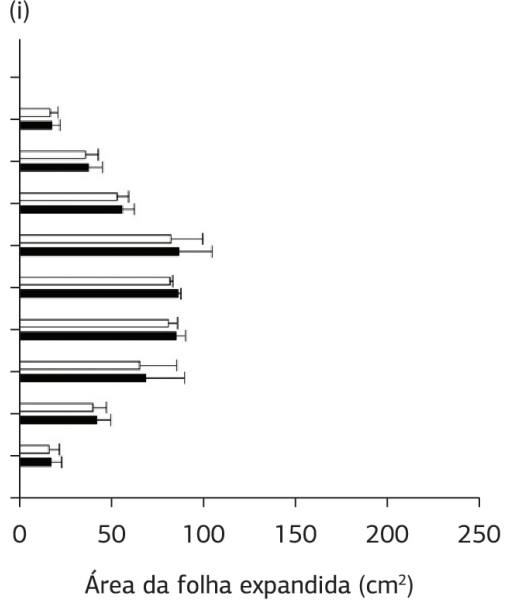

Figura 4. Perfil vertical da área da folha de gladíolo cultivado em três épocas: data de plantio: 2/9/11 - (a) Rose Friendship, (b) Peter Pears e (c) Jester; 4/1/12 - (d) Rose Friendship, (e) Peter Pears e (f) Jester; e 1.\%/6/12 11 - (g) Rose Friendship, (h) Peter Pears e (i) Jester; barras preenchidas representam a área calculada com equação específica para cada cultivar, ou seja, para Rose Friendship foi utilizada a equação $\mathrm{AF}=$ 0,6705.(C.L), para Peter Pears foi utilizada a equação $\mathrm{AF}=0,6269$.(C.L); para Jester foi utilizada a equação $\mathrm{AF}=0,6976$. (C.L); barras vazias representam a área calculada com a equação geral equação $\mathrm{AF}=0,664$.(C.L) para todas as cultivares.

ocorrendo variaçóes no formato entre diferentes cultivares de Gladiolus grandiflorus, o que reduz a necessidade de calibração das equações de regressão. Sugere-se, portanto, que a calibração seja necessária apenas para espécies de gladíolo que tenham diferenças morfológicas das folhas mais acentuadas, tais como espécies nativas do sul da África e regiōes mediterrâneas, que não são usualmente cultivadas para a produção de flores de corte.
O conhecimento do perfil vertical de área foliar no dossel da cultura é importante, pois indica como a área de folhas em diferentes posições da planta contribui para a $\mathrm{AF}$ total e o IAF da cultura. Em plantas de gladíolo, que apresentam de 7 a 12 folhas/planta, dependendo da cultivar (Tombolato, 2004), as duas primeiras folhas basais e a duas últimas folhas apicais são as menores, enquanto as folhas nas posiçôes 4, 5 e 6 são as maiores (Figura 4). Essa distribuição parabólica no 
tamanho das folhas também é observada em outras espécies vegetais, como Aspilia montevidensis (Fagundes et al., 2009). No caso do gladíolo, a hipótese é que as primeiras duas folhas são pequenas, pois o seu crescimento é dependente das reservas do cormo, já que a fotossíntese líquida na planta nesse estádio ainda é baixa, pois a área fotossintetizante é reduzida. À medida que mais folhas são emitidas na planta, a área fotossintetizante aumenta e assim aumenta a fotossíntese líquida e a disponibilidade de fotoassimilados para o crescimento das folhas, aumentando o seu tamanho na porção intermediária da planta. À medida que aumenta o número de folhas, a espiga que diferenciava quando a planta apresentava de três a quatro folhas visíveis (Shillo e Havely, 1976) também cresce no interior do cartucho da planta, e o crescimento da espiga representa o dreno principal na planta. Dessa forma, as folhas apicais apresentam grande competição por fotoassimilados com a espiga, o que certamente contribui para o menor tamanho das duas últimas folhas superiores da planta. A época de plantio não tem efeito no perfil vertical de área foliar, mas tem efeito sobre o tamanho das folhas (Figura 4), seguramente pelo efeito do ambiente que afeta a fotossíntese líquida do dossel, marcada pela disponibilidade de radiação solar e pela temperatura do ar, o que é mais notável em regióes extratropicais.

\section{CONCLUSÃO}

$\mathrm{O}$ modelo $\mathrm{AF}=\mathrm{a}$ (C.L), em que $\mathrm{C}$ é o comprimento da folha $(\mathrm{cm})$ e L é a maior largura da folha $(\mathrm{cm})$, é o mais indicado para a estimativa da área da folha em gladíolo. O fator de correçáo, representado pelo coeficiente $a$, varia pouco com a cultivar, podendo ser usado o valor de 0,644 para as cultivares Peter Pears, Amsterdã, Rose Friendship e Jester. O perfil vertical da área das folhas em gladíolo caracteriza-se por menores folhas na posição basal e apical e maiores folhas na posição intermediária.

\section{REFERÊNCIAS}

AHMAD, T.; AHMAD, I.; QASIM, M. Present Status and Future Prospects of Galdiolus Cultivation in Punjab, Pakistan. Journal of Tekirdag Agricultural Faculty, v.5, p.227-238, 2008.

AHMAD, I.; KHATTAK, A.M.; ARA, N.; AMIN, N.U. Effect of planting dates on the growth of gladiolus corms in Peshawar. Sarhad Journal of Agriculture, v.27, p.195-199, 2011.

AQUINO, L.A.; SANTOS JÚNIOR, V.C.; GUERRA, J.V.S.; COSTA, M.M. Estimativa da área foliar do girassol por método não destrutivo. Bragantia, v.70, p.832-836, 2011. http://dx.doi.org/10.1590/S000687052011000400015

BIANCO, S.; PITELLI, R.A.; PITELLI, A.M.C.M. Estimativa da área foliar de Typha latifolia usando dimensōes lineares do limbo foliar. Planta Daninha, v.21, p.257-261, 2003. http://dx.doi.org/10.1590/ S0100-83582003000200011
BIANCO, S.; PITELLI, R.A.; BIANCO, M.S. Estimativa da área foliar de Brachiaria plantaginea usando dimensōes lineares do limbo foliar. Planta Daninha, v.23, p.597-601, 2005. http://dx.doi.org/10.1590/ S0100-83582005000400006

CAMARGO, A.P.; SENTELHAS, P.C. Avaliação do desempenho de diferentes métodos de estimativa da evapotranspiração potencial no estado de São Paulo, Brasil. Revista Brasileira de Agrometeorologia, v.5, p.89-97, 1997.

CARGNELUTTI FILHO, A.; TOEBE, M.; BURIN, C.; FICK, A.L.; CASAROTTO, G. Estimativa da área foliar de nabo forrageiro em função de dimensôes foliares. Bragantia, v.71, p.47-51, 2012. http:// dx.doi.org/10.1590/S0006-87052012000100008

CHOUDHARY, M. MOOND, S.K.; KUMARI, A. Correlation Studies in Gladiolus. Research in Plant Biology, v.4, p.68-72, 2011.

FAGUNDES, J.D.; STRECK, N.A.; KRUSE, N.D. Estimativa da área foliar de Aspilia montevidensis (Spreng.) Kuntze utilizando dimensôes lineares. Revista Ceres, v.56 p.266-273, 2009.

LEITE, H.G.; ANDRADE, V.C.L. Um método para condução de inventários florestais sem o uso de equaçóes volumétricas. Revista Árvore, v.26, p.321-328, 2002. http://dx.doi.org/10.1590/S010067622002000300007

LIMA, C.J.G.S.; OLIVEIRA, F.A.; MEDEIROS, J.F.; OLIVEIRA, M.K.T.; OLIVEIRA FILHO, A.F. . Modelos matemáticos para estimativa de área foliar de Feijão-caupi. Caatinga, v.21, p.120-127, 2008 .

MARCHI, S.R.; MARTINS, D.; COSTA, N.V. Método não destrutivo de estimativa da área foliar de plantas daninhas de ambiente aquático: tanner-grass e capim-fino. Semina: Ciências Agrárias, v.32, p.1717-1724, 2011. http://dx.doi.org/10.5433/1679-0359.2011v32n4Sup1p1717

MARCOLINI, M.W.; CECÍLIO FILHO, A.B.; BARBOSA, J.C. Equações de regressão para a estimativa da área foliar de couve folha. Científica, v.33, p.192-198, 2005.

MARSHALL, J.K. Methods of leaf area measurement of large and small leaf samples. Photosynthetica, n.2, p.41-47, 1968.

SHILLO, R.; HALEVY, A.H. Inflorescence development of flowering and blasted gladiolus plants in relation to development of other plant parts. Scientia Horticulturae, v.4, p.79-86, 1976. http://dx.doi. org/10.1016/0304-4238(76)90068-6

SILVA, M.C.C.; FONTES, P.C.R.; VIANA, R.G. Estimativa da área da folha da batateira utilizando medidas lineares. Horticultura Brasileira, v.26, p.83-87, 2008. http://dx.doi.org/10.1590/S010205362008000100016

TOEBE, M.; FILHO, A.C.; LOOSE, L.H.; HELDWEIN, A.B.; ZANON, A.J. Área foliar de feijão-vagem (Phaseolus vulgaris L.) em função de dimensôes foliares. Semina: Ciências Agrárias, v.33, p.2491-2500, 2012

TOMBOLATO, A.F.C. Cultivo comercial de plantas ornamentais. Campinas: Instituto Agronômico, 2004. 221p.

WILLMOTT, C.J. On the validation of models. Physical Geography, v.2, p.184-194, 1981.

WILLMOTT, C.J.; ACKLESON, S.G.; DAVIS, J.J.; FEDDEMA, K.M.; KLINK, D.R. Statistics for the evaluation and comparison of models. Journal of Geophysical Research, v.90, p.8995-9005, 1985. http://dx.doi.org/10.1029/JC090iC05p08995 